Análise de parasitas presentes nas mãos e unhas dos manipuladores de alimentos da

$$
\text { feira livre de Barreirinhas - MA }
$$

Analysis of parasites in the hands and nails of food handlers of the Barreirinhas free fair - MA

Análisis de parásitos en las manos y uñas de los alimentadores de la feria gratuita de

\title{
Barreirinhas - MA
}

Recebido: 06/08/2020 | Revisado: 13/08/2020 | Aceito: 14/08/2020 | Publicado: 20/08/2020

\section{Bruno Nunes Costa}

ORCID: https://orcid.org/0000-0002-2228-7044 Instituto Federal de Educação, Ciência e Tecnologia do Maranhão, Brasil E-mail:brunonunes.bhs@gmail.com

Adriana de Mendonça Marques

ORCID: https://orcid.org/0000-0002-3587-538X Instituto Federal de Educação, Ciência e Tecnologia do Maranhão, Brasil E-mail:adriana.marques@ifma.edu.br

Monik Carvalho Canuto

ORCID: https://orcid.org/0000-0003-0816-765X Instituto Federal de Educação, Ciência e Tecnologia do Maranhão, Brasil E-mail: mcarvalhocanuto@gmail.com

Breno Nunes Costa

ORCID: https://orcid.org/0000-0003-0536-9037 Instituto Federal de Educação, Ciência e Tecnologia do Maranhão, Brasil E-mail:brenonunescosta3@gmail.com Cintya Marreiros Castro Canavieira ORCID: https://orcid.org/0000-0003-0446-5350 Instituto Federal de Educação, Ciência e Tecnologia do Maranhão, Brasil E-mail: cintya.mcc@gmail.com

João Janilson da Silva Sousa

ORCID: https://orcid.org/0000-0002-2929-7309 Instituto Federal de Educação, Ciência e Tecnologia do Maranhão, Brasil E-mail: janilsonpesquisapiaui@gmail.com 


\author{
Almerinda Macieira Medeiros \\ ORCID: https://orcid.org/0000-0002-3808-2035 \\ Instituto Federal de Educação, Ciência e Tecnologia do Maranhão, Brasil \\ E-mail:almerinda.medeiros@ifma.edu.br
}

\title{
Resumo
}

As feiras em sua maioria possuem aspectos higiênicos inadequados quanto à venda de alimentos, de modo que os feirantes atuando como manipuladores de alimentos, podem tornase vetores de patógenos para os alimentos e consequentemente para a população. Portanto, levando em consideração a falta de estrutura da Feira Livre de Barreirinhas e a falta de informações dos manipuladores quanto à higiene pessoal, resta-se analisar quais tipos de os parasitos presentes nas mãos e unhas dos manipuladores de alimentos do local em pauta, através da realização de coletas parasitológicas, a fim de analisá-las em Laboratório Específico. Nesse sentido, este estudo teve como objetivo analisar os tipos dos seres parasitológicos encontrados nos membros corporais aludido dos empreendedores da Feira Livre da cidade retrocitada e sensibilizá-los quanto aos cuidados sanitários. Os resultados mostraram a presença de micro-organismos patológicos nos corpos dos empreendedores, os quais são um perigo à saúde dos munícipes barreirinhenses. Por esse motivo, orientou-se o Poder Público Municipal a realizar atividades de Educação Sanitária e fiscalizações para o cumprimento das leis sanitárias vigentes na Nação Brasileira.

Palavras-chave: Barreirinhas; Feira livre; Feirantes; Parasitos.

\begin{abstract}
Most fairs have inadequate hygienic aspects regarding the sale of food, so that marketers acting as food handlers, can become vectors of pathogens for food and consequently for the population. Therefore, taking into account the lack of structure of the Feira Livre de Barreirinhas and the lack of information from the handlers regarding personal hygiene, it remains to analyze what types of parasites present in the hands and nails of the food handlers of the place in question, through conducting parasitological collections in order to analyze them in a Specific Laboratory. In this sense, this study aimed to analyze the types of parasitological beings found in the body members alluded to by the entrepreneurs of Feira Livre in the city mentioned above and to sensitize them regarding health care. The results
\end{abstract}


showed the presence of pathological microorganisms in the bodies of the entrepreneurs, which are a danger to the health of the citizens of Barreirinhas. For this reason, the Municipal Government was instructed to carry out Health Education activities and inspections to comply with the health laws in force in the Brazilian Nation.

Keywords: Barreirinhas; Free market; Fairkeepers; Parasites.

\section{Resumen}

La mayoría de las ferias tienen aspectos de higiene inadecuados con respecto a la venta de alimentos, por lo que los vendedores que actúan como manipuladores de alimentos pueden convertirse en vectores de patógenos para los alimentos y, en consecuencia, para la población. Por lo tanto, teniendo en cuenta la falta de estructura de la Feira Livre de Barreirinhas y la falta de información de los manipuladores sobre higiene personal, queda por analizar qué tipos de parásitos se presentan en las manos y las uñas de los manipuladores de alimentos del lugar en cuestión, a través de realización de colecciones parasitológicas para analizarlas en un laboratorio específico. En este sentido, este estudio tuvo como objetivo analizar los tipos de seres parasitológicos encontrados en los miembros del cuerpo aludidos por los empresarios de Feira Livre en la ciudad mencionada anteriormente y sensibilizarlos con respecto a la atención médica. Los resultados mostraron la presencia de microorganismos patológicos en los cuerpos de los empresarios, que son un peligro para la salud de los ciudadanos de Barreirh. Por esta razón, el gobierno municipal recibió instrucciones de llevar a cabo actividades de educación en salud e inspecciones para cumplir con las leyes de salud vigentes en la nación brasileña.

Palabras clave: Barreirinhas; Mercado libre; Fairkeepers; Parásitos.

\section{Introdução}

Desde os primórdios, os humanos sempre foram suscetíveis às doenças parasitológicas devido às migrações e os hábitos alimentares, assim como pela falta de instrumentos para a visualização de micro-organismos, e por esse motivo, sempre haviam notificações sobre doenças causadas por seres ocultos à visão humana (Fiori, Santos \& Silva, 2014)

Entretanto, com a descoberta do microscópio no século XVII, a realidade mudou, posto que a vida micro, outrora invisível, veio a ser visível, e por isso, tudo começou a fazer 
sentido na área da saúde, uma vez que vários protozoários foram descobertos e associados às enfermidades que assolavam o Homo sapiens (Sepel, Rocha \& Loreto, 2011).

Todavia, por mais que a ciência tenha descortinado o porquê de muitas patologias, a relevância da Parasitologia só se deu séculos mais tarde, quando a sociedade se deparou frente a vários desafios sanitários que imperavam e imperam até os dias de hoje, como por exemplo, o tratamento para a Leishmaniose, Trypanosoma cruzi, Toxoplasmose, Entamoebahistolytica e Plasmodium, os quais têm provocado danos sérios aos corpos dos seres humanos, e até mesmo, a morte destes, quando não tratados de forma correta (Almeida, Silva \& Medeiros, 2015).

Além disso, o estudo dos protozoários não se dá somente no laboratório, mas sim, no cotidiano das pessoas, quando elas vão ao supermercado, à feira, à escola, onde, de forma inerente, os indivíduos compram alimentos ou ingere água que podem carregar carga de parasitas, e com conseguinte, provocar malefícios ao seu bem estar pessoal (Piccolo \& Gagliani, 2013).

Com objetivo de minimizar as ocorrências de doenças parasitárias, é importante o desenvolvimento de ações de Educação Sanitárias (palestras, distribuição de folhetos informativos, fixação de cartazes, gincanas educativas com crianças e jovens), através de ações governamentais, em parceiras como as universidades, associações e demais ONGs que prestam serviços de extensão às comunidades, em especial, para as mais pobres, tendo em vista que estas são as que mais estão vulneráveis à tais enfermidades, dado que a falta de saneamento básico decente e de informações que atuem contra os parasitos são escassas na região onde habitam essa parcela da população (Araújo et al.,2014).

Sobre a importância da educação sanitária, Renovato e Bagnato (2011) escrevem:

Assim, o processo educativo em saúde deveria romper com a ignorância reinante nesse sertão. Portanto, a educação sanitária, suas concepções e suas construções discursivas, era considerada como a solução para vencer as condições precárias de saúde dos sujeitos rurais (p. 19). 
Contudo, para que haja uma verdadeira aprendizagem sobre Parasitologia, é indispensável sua aplicabilidade no dia a dia dos indivíduos, para que assim, os conhecimentos adquiridos numa ação extensionista possam ser solidificados e compartilhados entre todas as pessoas (Barbosa et al., 2012).

Vale salientar que os cuidados parasitológicos não se aplicam só a seres humanos, pelo contrário, eles se estendem a outros animais, os ditos "irracionais", tendo em vista que os protozoários também agem de forma maliciosa causando males à fisiologia destes e contribuindo para a disseminação de enfermidades que assolam a todo reino Animal, como exemplo, o Calazar, que atinge cães e gatos, e, também, pessoas, ocasionando óbito e sofrimento para suas vítimas (Alves et al., 2015).

Haja vista o explanado anteriormente, constata-se que a Parasitologia é meritória para todos indivíduos que habitam na Terra, dado que sem ela a vida seria mais difícil, em razão de que se teriam mais enfermidades, fomes e ausência de informações científicas sobre os seres parasitológicos, em especial, no que tange à alimentação humana, por isso levanta-se o seguinte problema: que tipos de parasitos as mãos e as unhas dos feirantes do Município de Barreirinhas/MA abrigam e que, conseguinte, podem contaminar os alimentos que são vendidos por estes à população local?

A respeito desta questão, pode-se afirmar preliminarmente o seguinte: I - os parasitas mais comuns nas mãos e unhas dos comerciantes são Etamoeba sp., Acares Lumbrícoides entre outros parasitos; II - os vendedores da local alvo do estudo precisam de uma ação sobre Educação Sanitária acerca dos seres invisíveis em foco.

Por isso, a fim de consolidar as perspectivas explanadas acima, o objetivo deste trabalho foi analisar os tipos dos seres parasitológicos encontrados nos membros corporais aludido dos empreendedores da Feira Livre da cidade retro citada. Este estudo se fez relevante, posto que não existe nos sites acadêmicos pesquisas são essa temática relacionadas ao Estado Maranhão, e muito menos ao Município supramencionado. 


\section{Metodologia}

A pesquisa consiste em análise laboratorial das amostras coletadas de microorganismos existentes nas unhas e mãos dos vendedores de comidas da Feira Livre de Barreirinhas/MA, baseado em dois métodos, quais sejam: métodos de Hoffman Adaptado e Hoffman Convencional, respectivamente, sendo que em ambos há a preparação das amostras pesquisadas em Laboratório Específico e observação dos sedimentos do material advindo desta em microscópio ótico (Oliveira, 2019).

Este trabalho foi realizado na sobredita cidade, município este que abriga mais de 62 mil pessoas, e que é conhecido por suas belezas naturais, como dunas e lagoas; o qual tem como economia local a agricultura, a pesca e macro e micro comércios dos mais variados gêneros, entre eles as pequenas quitadas na Feira Popular de Alimentos (Brasil, 2010).

Destaca-se que os pesquisadores se concentraram na dita localidade, pois esta é que tem maior fluxo dos trabalhadores mencionados, e, portanto, o número de alimentos vendidos ali é majoritário que no Mercado Público Municipal, que é outro estabelecimento que abriga feirantes, porém com fluxo humano menor.

A pesquisa teve as seguintes etapas (em todos as metodologias supracitadas): 1) realização de levantamentos bibliográficos por meio de artigos que tratam sobre a temática estudada, com o propósito de se granjear mais conhecimento no que tange ao tema pesquisado; 2)apresentação da pesquisa aos Feirantes, por meio de uma cartilha confeccionada pela equipe deste estudo; 3) coleta dos seres microscópios das mãos e unhas dos manipuladores de alimentos do local em questão, por meio do esfregaço com swabe; 5)Preparação das amostras em recipientes específico ; 6) Análise laboratorial, no Instituto Federal do Maranhão - Campus Barreirinhas; 7) escrita deste artigo.

Importante ressaltar que dentre os 40 inquiridos, 11 aceitaram participar desta pesquisa. Ainda, salienta-se que este trabalho almejava realizar divulgação dos resultados 
desta investigação ao público pesquisado, através de uma ação de educação sanitária, entretanto, com o auge dos números de casos da COVID-19 no Município de Barreirinhas/MA, essa etapa tornou-se malogradas.

\section{Resultados e Discussão}

Os resultados aqui apresentados são oriundos da pesquisa no já referido local com 11 feirantes, os quais tiveram os materiais parasitológicos de duas mãos e unhas coletados com o auxílio de material apropriado e específico.

A primeira participante apresentou um quadro parasitológico de cistos de ameba e ovos de Ascaris lumbricoides (Tabela 1):

Tabela 1 - Quadro parasitológico da Feirante 1

\begin{tabular}{|c|c|c|}
\hline O que vende: & \multicolumn{2}{|c|}{ Juçara } \\
\hline \multirow{2}{*}{ Idade: } & Mome do parasita & Quantidade \\
\hline \multirow{2}{*}{$\begin{array}{c}\text { Parasitos } \\
\text { encontrados: }\end{array}$} & Cistos de ames de idade \\
\cline { 2 - 3 } & Ovos de Ascaris lumbricoides & 5 \\
\cline { 2 - 3 } & & 6 \\
\hline
\end{tabular}

Fonte: Autores da pesquisa.

$\mathrm{Na}$ amostra da segunda feirante, encontrou-se grande quantidade de ovos de Ascaris lumbricoides (Tabela 2): 
Research, Society and Development, v. 9, n. 9, e304997392, 2020

(CC BY 4.0) | ISSN 2525-3409 | DOI: http://dx.doi.org/10.33448/rsd-v9i9.7392

Tabela 2 - Quadro parasitológico da Feirante 2

\begin{tabular}{|c|c|c|}
\hline O que vende: & \multicolumn{2}{|c|}{ Verduras } \\
\hline Idade: & Mais de 30 anos de idade \\
\hline Parasitos & Nome do parasita & Quantidade \\
\hline \multirow{2}{*}{ encontrados: } & Ovos de Ascaris lumbricoides & 6 \\
\cline { 2 - 3 } & & \\
\hline
\end{tabular}

Fonte: Autores da pesquisa.

No que diz respeito à terceira trabalhadora, obteve-se na amostra parasitos como Entamoeba sp. e cistos desta (Tabela 3):

Tabela 3 - Quadro parasitológico da Feirante 3.

\begin{tabular}{|c|c|c|}
\hline O que vende: & \multicolumn{2}{|c|}{ Verduras } \\
\hline Idade: & No anos de idade \\
\hline \multirow{2}{*}{$\begin{array}{c}\text { Parasitos } \\
\text { encontrados: }\end{array}$} & Entamoeba sp. & Quantidade \\
\cline { 2 - 3 } & & 1 \\
\cline { 2 - 3 } & Cisto de Entamoeba sp. & 8 \\
\hline
\end{tabular}

Fonte: Autores da pesquisa.

Em relação à quarta vendedora, o resultado encontrou-se ovos de Ascaris lumbricoides e o parasita Trichuris trichiura (Tabela 4): 
Tabela 4 - Quadro parasitológico da Feirante 4

\begin{tabular}{|c|c|c|}
\hline O que vende: & \multicolumn{2}{|c|}{ Peixe } \\
\hline \multirow{2}{*}{ Idade: } & Nome do parasita & Quantidade \\
\hline \multirow{3}{*}{$\begin{array}{c}\text { Parasitos } \\
\text { encontrados: }\end{array}$} & Ovo de Ascaris lumbricoides & 1 \\
\cline { 2 - 3 } & & 3 \\
\cline { 2 - 3 } & Trichuris trichiura & \\
\hline
\end{tabular}

Fonte: Autores da pesquisa.

Concernente aos trabalhadores da feira que foram identificados por números e seus nomes suprimidos: a vendedora de peixe (5), vendedora de verduras (6), vendedora de verduras (7), das análises parasitológicas vendedora de verduras (8), vendedora de frutas e verduras (9), vendedora de verduras (10) e vendedora de peixe (11), resultando de 63,6\% dos trabalhadores analisados apresentaram resultados negativos nas análises parasitológicas, ou seja, não haviam a presença de protozoários e helmintos nas mãos e unhas das pessoas.

Compulsando os autos deste trabalho constata-se que a maioria das feirantes alvos do estudo, realmente, têm práticas de educação sanitárias factuais, dado que a maioria apresentou resultados de inexistências a parasitas nas análises laboratoriais. Segundo Renovato (2011) isso se dá devidos aos vários programas de saúde social que os governos passaram a desenvolver nas últimas décadas com as pessoas mais pobres, a fim de conscientizar essa parcela da população brasileiras acerca dos perigos que a falta de higiene pode provocar aos seres humanos, em especial, àqueles que nunca tiveram acesso a um saneamento básico gratuito de qualidade.

Todavia, é preocupante a situação das quatro primeiras feirantes, visto que estas estão com altos números de parasitos em suas mãos e unhas, e pior, com microrganismos 
extremamente perigosos às suas saúdes, como exemplo, a ameba, a qual pode causar graves consequências à vendedora e aos seus clientes, causando sérias dores abdominais e até a morte (Oliveira, 2016).

Ademais, a presença dos seres parasitológicos no corpo das participantes aduzem à falta de higiene que as trabalhadoras estão tendo no seu dia a dia como profissionais, pois, com certeza, parte dessa contaminação são oriundas das cédulas de dinheiros que estas recebem e repassam em suas quitandas, isto é, elas não estão fazer a higienização das mãos ao venderem seus produtos, o que pode ocasionar sérias eventualidades administrativas perante os Órgãos de Saúde Municipal, inclusive, com multa e encerramento das atividades profissionais destas (Aguiar \& Lamounier, 2014).

Entretanto, a responsabilidade da saúde das labutadoras e da qualidade das comidas vendidas na Feira Livre não é somente das laboriosas, mas, principalmente, do Poder Público Municipal, que tem a incumbência de fiscalizar, e sobretudo, orientar e educar os vendedores no que se relaciona aos cuidados sanitários que todos os vendedores, bem como seus clientes têm que ter sobre como desenvolver uma venda/compra de alimentos sem que haja fluxo cruzado em ambas as etapas, com a finalidade de preservar a Saúde Pública da localidade pesquisada e garantir um padrão sanitário de qualidade (Souza, 2012).

Além disso, é inerente que as pessoas que testaram positivo a parasitos, possam ser orientadas a procurarem um atendimento médico, para que assim, possam se consultar e receber as devidas medicações, com o intuito de eliminar os parasitas identificados no Laboratório de Biologia (Ferreira, 2016).

Ex expositis, nota-se há necessidade de mais informações aos feirantes barreirinhenses, vez que a falta de educação sanitária é algo corriqueiro na Feira de Barreirinhas/MA, conforme mostrado anteriormente, e por isso, é necessário que os agentes públicos, bem como os vendedores ajam corretamente, para que não se tenha doenças causadas por alimentos entre os munícipes da cidade citada, caso contrário, existe um perigo eminente em relação às saúdes dos empreendedores e compradores dos alimentos 
comercializados na localidade supra dita (Souza \& Atayde, 2017).

\section{Considerações Finais}

Delineou-se realizar um estudo com o título "Análise de micro-organismos presentes nas mãos e unhas de manipuladores de alimentos na Feira Livre de Barreirinhas - MA, tendo em vista que um estudo como este é atinente para que as sociedades cível e acadêmica conheçam a realidade parasitológica que o local de estudo de que fala precisa ser conhecido, e acima de tudo, ajudado, considerando que existe, sim, manipuladores de alimentos quitandeiros portadores de micro-organismos patogênicos à Saúde Humana da população barreirinhense. .

À vista disso, para fins de se ter um propósito único da investigação, designou-se o objetivo geral de analisar os tipos dos seres parasitológicos encontrados nas mãos e unhas dos feirantes da cidade em epígrafe, o qual foi atingido, já que se conseguiu resultados significativos e demonstrativos sobre à Educação Sanitária das pessoas pesquisadas, os quais foram explicitados neste trabalho.

Se observa que as hipóteses elencadas neste artigo foram corroboradas, visto que vários parasitos mencionados nelas foram encontrados nas amostras laboratoriais, bem como os resultados demonstraram que a comunidade feirante necessita, com urgência, de ações que a ensinam como manipular mantimentos alimentares corretamente

No entanto, por mais que a pesquisa tenha logrado êxito, esta teve duas partes interrompidas, que eram o estudo microbiológico do material coletado e uma atividade de Educação Sanitária com os comerciantes pesquisados, nada obstante, isso foi impedido em virtude da Pandemia do Novo Coronavírus, dado que esta fechou o Laboratório de Biologia para análises das bactérias e tornou perigoso o contato pessoal com os quitandeiros. Porém, a relevância das informações neste artigo é meritória e fundamentais para todos os brasileiros.

Além disso, para que exista uma segurança por em relação à manipulação dos 
alimentos vendidos na Feira, a Prefeitura do Município deve efetuar as seguintes ações:

Realize ações que ensinam os feirantes com relação às práticas corretas de manuseios das comidas comercializadas na localidade em pauta;

Que fiscalize o cumprimento das normas sanitárias vigentes nas legislações nacionais, com o objetivo de prezar pela saúde dos vendedores e compradores dos gêneros alimentícios vendidos no local pesquisado.

Realizando isso, com toda certeza, Barreirinhas terá uma Feira Livre fornecedora de produtos comestíveis de qualidade e higiene apropriada, conforme as leis sanitárias existentes no Brasil.

\section{Referências}

Aguiar, N. S.; Lamounier, T. A. C. (2014) Pesquisa de cistos de protozoários e ovos de helmintos em cédulas de dinheiro na cidade do Gama-DF. Acta de Ciências e Saúde, v. 2, n. 2, p. 1-13.

Alves, M. de L. et al. (2015). Leishmaniose visceral e aspectos socioambientais: relatos sobre a doença em área periurbana da região metropolitana de Natal (RN), Brasil. Revista Brasileira de Ciências Ambientais (Online), n. 38, p. 109-122.

Almeida, F.; Silva, R.; Medeiros, J. (2015). Ocorrência de helmintos e protozoários intestinais em idosos. Journal of Biology \&amp; Pharmacy and Agricultural Management, v. 10, n. 2.

Barbosa, L. de A. et al. (2012). A educação em saúde como instrumento na prevenção de parasitoses. Revista Brasileira em Promoção da Saúde, v. 22, n. 4, p. 272-278.

Brasil, Instituto Brasileiro de Geografia e Estatística. (2010). Cidade de Barreirinhas. Brasília, 2010. Disponível em: <https://cidades.ibge.gov.br/brasil/ma/barreirinhas/panorama>. Acesso em: 29 abr. 2019. 
Ferreira, A. V. T. et al. (2016). Contribuição do médico veterinário na educação dos proprietários de cães e gatos sobre o tratamento e controlo das parasitoses. Dissertação de Mestrado.

Fiori, M. M.; Santos, C. F. M. dos; ilva, R. D. C. da. (2014). Doenças e parasitos tropicais na expansão interior do Império Colonial português na América: o caso das monções. Territórios e Fronteiras, v. 7, n. 1, p. 165-182.

Junior, J. V. C.; Stopiglia, C. D. O.; Nicorena, K. (2016). A monitoria no ensino da Microbiologia para cursos de Fisioterapia e Enfermagem na UNIPAMPA. Anais do Salão Internacional de Ensino, Pesquisa e Extensão, v. 7, n. 1.

Levinson, W. (2016). Microbiologia médica e imunologia. McGraw Hill Brasil.

Moreira, A. S. et al. (2019). Pesquisa de Parasitos Intestinais em crianças de um Centro de Educação Infantil em um Município no Sul de Minas Gerais. Revista da Universidade Vale do Rio Verde, v. 17, n. 1.

Oliveira, A. A. (2019). Pesquisa de Balantidium coli em água de laboratório de análises clínicas através do método de Hoffman. Jornal de Ciências Biomédicas e Saúde, v. 3, n. 3, p. 147.

Oliveira, D. M. et al. (2016). Perfil parasitológico do cheiro verde comercializado em feiras livres de Imperatriz-MA. Biota Amazônia (BioteAmazonie, Biota Amazonia, Amazonian Biota), v. 6, n. 2, p. 123-126.

Piccolo, L.; Gagliani, L. H. (2013). Estudo da prevalência de helmintos e protozoários em notas de dinheiro (papel moeda) em circulação na baixada santista. UNILUS Ensino $e$ Pesquisa, v. 5, n. 9, p. 13-20.

Renovato, R. D.; Bagnato, M. H. S. (2011). Educação Sanitária e o Serviço Especial de Saúde Pública (1942-1960): A doença não conhece fronteiras. Hist. Enf. Rev. Eletr, v. 2, p. 105-125. 
Sepel, L. M. N; Rocha, J. B T da; Loreto, E. L. S. (2011). Construindo um microscópio II. Bem simples e mais barato. Revista Genética na Escola, v. 6, p. 1-5.

Souza, É. M. de et al. (2012) Educação sanitária: orientações e práticas federais desde o Serviço de Propaganda e Educação Sanitária ao Serviço Nacional de Educação Sanitária (1920-1940). Tese de Doutorado.

Souza, T. M. de; Atayde, H. M. (2017). Educação higiênico-sanitária dos feirantes do Mercadão 2000 e Feira do Pescado em Santarém-PA. Revista Brasileira de Extensão Universitária, v. 8, n. 3, p. 127-134.

\title{
Porcentagem de contribuição de cada autor no manuscrito
}

\author{
Bruno Nunes Costa $-15 \%$ \\ Adriana de Mendonça Marques - 15\% \\ Monik Carvalho Canuto - 15\% \\ Breno Nunes Costa - 15\% \\ Cintya Marreiros Castro Canavieira - 15\% \\ João Janilson da Silva Sousa - 15\% \\ Almerinda Macieira Medeiros - 15\%
}

